\title{
Is there still a need for CTW?
}

\author{
P. Carlo Cacciabue • Oliver Carsten • \\ Frédéric Vanderhaegen
}

Published online: 2 July 2014

(C) Springer-Verlag London 2014

\section{Introduction}

A changing of the editorial guard at CTW is a good moment to reflect on the research domain addressed by the journal and on what new challenges the research community in people, technology and organisations might need to address. So we take this opportunity to look back over the last 15 years and to identify some new opportunities for research in the area of interaction between technology and people, focussing on two areas that are fundamental to the journal.

\section{Looking back}

In 1999, when CTW started, the main mission of the Journal was "to bring together research that normally resides on the borderline between people, technology and organisations..." Its main focus was identified as "the study of people at work from a socio-technical and cognitive systems perspective" which demanded "research in background disciplines such as cognitive systems

\section{P. C. Cacciabue}

Dip. di Ing. Aerospaziale Politecnico Milano, Campus Bovisa Sud, Via La Masa 34, 20156 Milan, Italy

e-mail: carlo.cacciabue@gmail.com

O. Carsten $(\square)$

Institute for Transport Studies (ITS), University of Leeds, 34-40 University Road, Leeds LS2 9JT, UK

e-mail: O.M.J.Carsten@its.leeds.ac.uk

F. Vanderhaegen

LAMIH, Université de Valenciennes et du Hainaut-Cambrésis, Le Mont Houy, 59313 Valenciennes Cedex 9, France

e-mail: frederic.vanderhaegen@univ-valenciennes.fr engineering, human factors and cognitive ergonomics... at both a theoretical and a practical level" (Hollnagel and Cacciabue 1999). This mission was associated to a "credo": respect for Intellectual Property and emphasis on quality of work as being the leading influences guiding the selection of topics and the excellence of contributions, in all domains of application. The result is that CTW can be seen as a "window" into the impact of human factors and cognitive science in designing, developing, assessing and validating different working contexts, where collaboration between actors is essential, independently of the fact that they are humans or machines.

There are different ways to evaluate what the Journal has achieved in these almost first 15 years of publication. One possible way is to follow the image of a window over the areas and domains of interest and scan through the journal issues. Focusing on domains of application, it is possible to look for energy/nuclear production (CTW, 2 (4), 2000; CTW, 15 (1), 2013), process and chemical industry (Salo and Svenson 2003; Baranzini and Christou 2010), manufacturing industry (Barroso and Wilson 2000; Upton et al. 2010), road transport (CTW, 8 (3), 2006a, b), maritime transport (Itoh et al. 2001; van Westrenen and Praetorius 2014), rail transport (CTW, 8 (1), 2006a, b) and aviation (Dekker and Woods 1999; Masson and Koning 2001; Rashid et al. 2013), household (CTW, 5 (1), 2003), healthcare (McCarthy and O'Connor 1999; Xiao and Sanderson 2013; Parush et al. 2014) and social services and emergency management (Militello et al. 2007; Kylesten and Nählinder 2011). Although in some cases the societal impact of certain events has increased the attention on specific issues (Johnson 2005), in general, the need to keep under attention the role of humans in managing systems and interacting with the actual control systems of real processes has always been favoured. 
Focusing on application areas, the impact and human contribution at the level of design, risk assessment and evaluation of plants has been the main locus of attention. In particular, the aim to for methods that go beyond the more established approaches associated to the concepts of "classical" HMI interaction and automatic control, has been constantly fostered, considering collaborative activities and distributed systems (Dekker and Woods 2002; Shalin 2005; Inagaki 2006; Vanderhaegen et al. 2006; Smith et al. 2007; CTW, 15 (1), 2013), cognitive systems engineering (Norros and Salo 2009; Inagaki 2010) and coordination in high-risk organizations (Grote et al. 2009), etc.

At a technical level, several topics involve the role of the joint-cognitive system of humans and control systems, primarily: decision-making, human machine interfaces, field studies and human related conditions that affect behaviour and error making, such as stress, workload, emotions and sensations. All of these aspects have always been popular. Decision-making - in particular in dynamic conditions - and team interaction have been constantly present and still play a very important role (Rogalski 1999; Kontogiannis 1999; Johnson 2002; Roth et al. 2004; Vanderhaegen 2010; Karikawa et al. 2013). Moreover, it can be noticed that emotional and personality factors have gradually become more and more relevant in different domains (Saad 2006; Nemeth 2007; Cacciabue and Cassani 2012; Perry and Wears 2012; Barnard et al. 2014).

All the above-mentioned studies are associated to theoretical frameworks, methods and modelling. In CTW, these elements have always been placed at the centre of the manuscripts that have been published. The idea is that any practical implementation must be sustained by a solid framework built on a theoretical method or model. Then, these must be described so that they can be applied or replicated by others in different domains for similar problems. In particular, attention has been placed on "new" methods and techniques of relevance for CTW. Therefore, in addition to the "typical" focus on joint-cognitive modelling and human reliability (Woods et al. 2002; Dekker and Hollnagel 2004; Healey and Benn 2009; Cacciabue 2010), special attention has been dedicated to theories and methods associated to Cognitive Work Analysis (Turner and Turner 2001; Miller et al. 2006; Xiao and Sanderson 2013), Ethnography (Farrington-Darby and Wilson 2009) and Resilience Engineering (Woods and Cook 2002; Re and Macchi 2010; Nemeth et al. 2011; Nemeth 2012; Hollnagel 2012).

Several questions can be raised at this point. As an example: has CTW achieved and fulfilled its alleged mission? It is not really up to the editors to respond, but certainly the Founding Editors have sought to work with dedication in that direction. Another important question may be whether it is possible to improve and/or whether CTW has a perspective? In both cases, the answer is simple and immediate. Yes, it is possible to improve, as improving is at the very heart of research and as long as there are "authors", we can expect that they will provide better and better research in favour of mankind and science, and consequently better papers and manuscripts. In terms of perspective, we believe that CTW has a long future, as the subject matter of the journal is associated with human beings, their working contexts and "their tools". These three components will always exist as long as the first one of them exists. Thus, the Journal will continue to be relevant, as long as there are authors and editors willing to pass the "baton" and keep running and working with dedication (and enjoyment) as has been the case in the past 15 years.

\section{What are potential new topic areas for CTW?}

\subsection{Automation expanding into new domains}

Our era is one in which automation is becoming pervasive, smarter, more autonomous and more connected (e.g. the internet of things). Until fairly recently, the predominant domain for automation was the workplace, going back at least to the roll-out of mass production and the introduction of the assembly line in the sphere of manufacturing in the early twentieth century. In the 1950s came automation in process industries, followed by automation in system management in such areas as air traffic control and in the control of technologically advanced and expensive vehicles such as airplanes and ships. In the domestic sphere, automation tended to be trivial, involving for example the replacement of manually controlled washing machines with "automatic" machines, which actually still required a great deal of human interaction and control. Thus, most persons, if they encountered automation in any significant way, did so in the context of work or in interactions where the automation was hidden from the user as in the case of road traffic signals.

Now automation is invading every sphere of life and is almost impossible to avoid. We have connected thermostats replacing time switches in the control domestic heating and cooling, and we have the dubious pleasure of interacting with automated telephone call management centres. With far more serious implications for human factors and safety, automation is now invading personal transport, where previously it was restricted to the provision of public transport. The Google Car may in part be hype but it does represent what could become a gamechanging mode of transport. We already have a the penetration of many kinds of automated support systems into the driving domain-electronic stability control, adaptive 
cruise control and automated emergency braking. We are on the cusp of driving vehicles with simultaneous automation of lateral and longitudinal control. In terms of emergency situations, almost all the vehicle manufacturers are developing crash avoidance systems with both braking and swerving authority (e.g. Isermann et al. (2008); InteractIVe project), while very high automation of continuous vehicle control is soon to be on offer (e.g. Cadillac Supercruise). We are entering this brave new world of automation in personal transport with comparatively little research on the human factors issues. Were there to be as little regulatory oversight in civil aviation as there is over the assistance and automation systems in cars and trucks, there would be an outcry. Instead, we may well see the handover of the operation of a public realm, i.e. road space, to a multitude of completely uncoordinated and perhaps even incompatible systems.

This gives rise to the question of whether we can transfer knowledge and design good practice from commercial aviation to road traffic. Of course, it makes sense to reflect on whether the lessons learned in applying automation to civil aviation are relevant to the road vehicle domain and many authors have indeed argued that there are indeed major lessons to be learned (e.g. Stanton and Marsden 1996; Young et al. 2007). However, it can also be posited that the two domains are radically different-in the number and variety vehicles in service, in the training and professionalism of the operators, in the rigour of vehicle maintenance, in the prescription of routing and speed and in the potential for interaction with humans not in mechanically controlled vehicles (see e.g. Harris and Harris 2004). One simple illustration of the striking differences between the domains of commercial aviation and road traffic is that there are some 20,000 commercial airplanes in operation worldwide, as compared to 1 billion road vehicles (Ward's Automotive 2011). So automation of driving presents new challenges and requires its own line of research.

Another trend is that automation of a serious kind with considerable authority is moving from very structured environments (aviation, production lines and chemical plants) to more unstructured domains_-driving, the home, etc. In the former, organisational aspects have often been paramount (see e.g. Reason 1997) and sensible function allocation principles (Fitts 1951; de Winter and Dodou 2014) are routine. In the latter, cultural and attitudinal aspects need to be given far more consideration as to a large extent the behaviour of individuals, their error propensity and even their willingness to engage in risky behaviour may be the limiting factors. Individuals may also choose to use automation inappropriately, i.e. for reasons of personal motivation, and so transgress principles of function allocation. An example would be the use of a Lane
Departure Warning System as an aid to driving in conditions when drowsiness is likely to occur. That some drivers view LDW as an assistance for driving when tired was confirmed in a survey of users conducted in the AIDE project (Portouli et al. 2006). This is a violation of one of the basic requirements for effective function allocation between the human and the automated agent: "each agent must be allocated functions that it is capable of performing" (Feigh and Pritchett 2014). Here, we have an instance of using automation to assist in non-capable performance of driving.

This creates a need to give far more attention to individual aspects and to catering to less homogeneous populations and environments. Work on creating models of behavioural adaptation to different levels and type of automation needs to take place. It is interesting here to note that a recent review of behavioural adaptation in the driving and road safety domain hardly makes any reference at all to automation (Rudin-Brown and Jamson 2013). Models combining personality and cognitive aspects in the driving domain have been proposed (e.g. Rudin-Brown and Noy 2002; Carsten 2007; Cacciabue and Carsten 2009), but they have not been extended or applied to automation. Currently, the literature on modelling of function allocation between humans and automation tends to focus almost exclusively on cognitive aspects, ignoring behavioural issues (see e.g. Pritchett et al. 2014).

A further set of challenges lies beyond operator interaction with the vehicle or device in the area of how design should manage external interactions. For driver-vehicle units are not autonomous-they do not drive on empty roads. Drivers must continuously interact with other driver-vehicle units and with pedestrians, cyclists, motorcyclists and even animals (both ridden or steered and unridden). Automated vehicles will similarly have to interact with all these other road users. That will require not only interpretation of the intentions of the other road user, which even human drivers do not always manage successfully, but also successful interpretation of the intentions of the automated vehicle by the other road users. Here again is a field that is ripe for exploration.

Such interaction between road users and automated vehicles can be likened to human-robot interaction. Robots are escaping from the factory and will very likely permeate many aspects of daily life. They will assist the elderly and infirm, patrol the streets for crime prevention and detection, inspect dangerous locations (such as nuclear power stations), provide rescue in floods and other natural disasters and perform hard physical labour in farming. If then robots become pervasive, what are the design and human-system challenges? Will the robot-carer assisting an elderly person correctly interpret the needs of that person and will the elderly person comprehend the communications and 
intentions of the robots? And will the robot know how to deal with critical and emergency situations? Will the robots require remote monitoring at all times and if so how will operator attention in the monitoring centre be maintained? These are major challenges in health care.

\subsection{What are the future challenges for risk analysis?}

Many papers in CTW have contributed to the development and the validation of risk analysis methods for the study of technical, human and organisational factors. Risk analysis consists mainly of identifying undesirable risks in terms of occurrence and consequences of events, and at making them acceptable by proposing new system functional specifications that suppress these undesirable risks. Various communities are involved in such a process: engineering sciences, social sciences, cognitive sciences. Several solutions can result from these analyses: the integration of technology to control particular unsafe events, the development of specific training programmes to make human operators sensitive to the management of unsafe scenarios, the control of task or function allocation between decisionmakers, the definition of degrees of automation, etc. These solutions are efficient, and their associated methods are continuously being improved to expand their scope, but are they sufficient?

The use of information systems such as on-board automated systems for cars presents sometimes operational risks that were not taken into account with classical risk analysis methods. For instance, the ABS system was designed for safety reasons: it prevents the wheels from locking in an emergency braking. For most of users of this system, it is a comfort system that allows them to drive faster and reduce separation distances in the belief that it improves the braking performance of their vehicle (Vaa 2013). This is a typical dissonance between the risks assessed by the designer of a system and the risks perceived and controlled by the users of this system. The simple example shows how a system function can evolve and be different between group of people such as the designers and the users of a given system. Here, we have a case of behavioural adaptation that illustrates how the functional stability of a system is not guaranteed.

More generally, the stability of a system relates to a sustainable equilibrium of its functioning around a predefined value or point, or around an interval of points of values. Outside this given reference, the system state is unstable and any deviation from this reference generates risks that may affect criteria such as safety, productivity, quality, human workload, etc.

Classical risk analysis focuses on the identification and the control of undesirable events and aims at providing the human-machine systems with barriers in order to protect them from the occurrence or the impact of these events. Despite these barriers, accidents remain and retrospective analyses can help the designers to identify what was wrong. Safety-based analysis can apply different methods. The RAMS-based methods (Reliability, Availability, Maintainability and Safety-based analyses) are concerned with technical failures. Human reliability or human error-based analyses focus on the success or the failure of human behaviours, respectively. Results of such analyses are mainly offline, static and mono-criterion (i.e. safety analysis) without taking into account that the field analysis made by the users or the human operators are online, can evolve over time and integrate several criteria such as safety, activity quality, or production, workloads, etc. Methods for online multi-criteria risk analysis and usercentred analysis are then required for both short-term and long-term perspectives.

More recently, resilience- or vulnerability-based methods consider the analysis of the success or the failure of the recovery control of the system stability, respectively (Hollnagel et al. 2006; Zieba et al. 2010; Ouedraogo et al. 2013). These approaches aim at identifying the technical, human and organisational factors that make a system resilient or vulnerable in the face of particular situations such as unpredictable or unprecedented events. The main difficulty for such approaches is to predict the unpredictable or the unprecedented! These approaches will be useful for designing resilient systems and take advantages of contributions from various applications: the medical domain, psychology, production systems, computer science, transport, robotics, or ecology for instance.

The design of a human-machine system requires the control of its stability, i.e. the control of its sustainable equilibrium after the occurrence or the consequences of particular events. The resilience concept is adequate for that purpose. Indeed, it relates to the management of stable or unstable states of a system in order to: to maintain the system stability whatever the perturbations; to return to a new stable state or to a previous stable state after the occurrence or the consequences of perturbations; to avoid or to recover any loss of control; to control the holistic stability of the system; or to control the individual stability of the decision-makers that may affect this global stability. Future research may then be done for such study of system stability.

However, is it correct to try to maintain stability for safety reasons? Dissonance generated artificially aims at breaking such stability and at improving knowledge by active learning (Aïmeur 1998). Such a breakdown of system stability may identify risks associated with monotonous activity or repetitive activity, e.g. risks of hypovigilance, risks of inattention, or risks of human error, etc. 
Dissonance engineering is another perspective for studying risks of the stability of a given system use. A cognitive dissonance is defined as an incoherence between individual cognitions (Festinger 1957). Cindynics dissonance is a collective or an organizational dissonance related to incoherence between persons or between groups of people, e.g. designers versus users (Kervern 1995). Various recent contributions on dissonance study show the current interest the scientific community has for this concept (Chen 2011; Telci et al. 2011; Vanderhaegen 2013).

The management of dissonances requires the reinforcement of knowledge by applying different strategies of learning in order to learn from negative and positive feedbacks related to dissonance management. This needs the adaptation or the development of specific learning algorithms or tools (e.g. case-based reasoning systems, neural network-based systems, genetic algorithms, etc.) to refine, modify, delete or create knowledge.

Several dissonances have already been studied: automation surprise, barrier removal, erroneous affordances, lack of sense-making, lack or loss of knowledge, etc. This list is not exhaustive and a more detailed taxonomy of dissonances and associated methods to assess these dissonances are required. This will extend the risk analysis process of a human-machine system based on the stability of some decision-makers' characteristics such as knowledge, availability, prescription, or preferences.

Future CTW contributions may then study such new challenges based on the system stability for risk analysis, regarding short-term and long-term delay of use, taking into account high and low levels of stability variation such as weak signals that are not directly perceived or not directly considered as important and that may provoke accidents.

\section{Conclusion}

Our view, perhaps not surprisingly is that CTW still has a vital role. The fundamental proposition which gave rise to the journal is still correct. Some new challenges have been identified above, which is only natural as technologies and methods of managing systems develop. But of course, the contributors to the journal are ingenious and will themselves generate their own new topics. We can look forward to that.

\section{References}

Aïmeur E (1998) Application and assessment of cognitive dissonance: theory in the learning process. J Univ Comput Sci 4(3):216-247
Automotive Ward's (2011) Vehicles in operation by country. Southfield, Michigan

Baranzini D, Christou MD (2010) Human factors data traceability and analysis in the European Community's Major Accident Reporting System. Cogn Technol Work 12(1):1-12

Barnard Y, Carsten O, Lai F (2014) From a theoretical model to a predictive simulation model of operator interaction with support systems: designing experiments to build the numerical simulation. Cogn Technol Work 16(1):117-129

Barroso MP, Wilson JR (2000) Human error and disturbance occurrence in manufacturing systems (HEDOMS): a framework and a toolkit for practical analysis. Cogn Technol Work 2(1):51-61

Cacciabue PC (2010) Dynamic reliability and human factors for safety assessment of technological systems: a modern science rooted in the origin of mankind. Cogn Technol Work 12(2):119-131

Cacciabue PC, Carsten O (2009) A simple model of driver behaviour to sustain design and safety assessment of automated systems in automotive environments. Appl Ergon 41(2):187-197

Cacciabue PC, Cassani M (2012) Modelling motivations, tasks and human errors in a risk-based perspective. Cogn Technol Work 14(3):229-241

Carsten O (2007) From driver models to modelling the driver: what do we really need to know about the driver. In: Cacciabue PC (ed) Modelling driver behaviour in automotive environments: critical issues in driver interactions with intelligent transport systems. Springer, London, pp 105-120

Chen TY (2011) Optimistic and pessimistic decision making with dissonance reduction using interval-valued fuzzy sets. Inf Sci 181(3):479-502

CTW (2000) Special issue on the JCO accident: the rational choice of “error". In: Cacciabue PC, Fujita Y, Furuta K, Hollnagel E (eds) Cogn Technol Work 2(4)

CTW (2003) Special issue on interacting with technologies in household environments. In: Baillie L, Benyon D, Bødker S, Macaulay C (eds) Cogn Technol Work 5(1)

CTW (2006a) Special issue on rail human factors. In: Wilson J, Norris, B (eds) Cogn Technol Work 8(1)

CTW (2006b) Special issue on human-centred design in automotive systems. In: Cacciabue PC (ed) Cogn Technol Work 8(3)

CTW (2013) Special issue on human factors in nuclear safety. Im: Healey AN, Cacciabue PC, Berman J (eds) Cogn Technol Work $15(1)$

De Winter JCF, Dodou D (2014) Why the Fitts list has persisted throughout the history of function allocation. Cogn Technol Work 16:1-11

Dekker SWA, Hollnagel E (2004) Human factors and folk models. Cogn Technol Work 6(2):79-86

Dekker SWA, Woods DD (1999) To intervene or not to intervene: the dilemma of management by exception. Cogn Technol Work 1(2):86-96

Dekker SWA, Woods DD (2002) MABA-MABA or abracadabra? Progress on human-automation co-ordination. Cogn Technol Work 4(4):240-244

Farrington-Darby T, Wilson JR (2009) Understanding social interactions in complex work: a video ethnography. Cogn Technol Work 11(1):1-15

Feigh KM, Pritchett AR (2014) Requirements for effective function allocation: a critical review. J Cogn Eng Decis Mak 8(1):23-32

Festinger L (1957) A theory of cognitive dissonance. Stanford University Press, Stanford

Fitts PM (ed) (1951) Human engineering for an effective airnavigation and traffic-control system. Committee on Aviation Psychology, National Research Council, Washington 
Grote G, Weichbrodt JC, Günter H, Zala-Mezö E, Künzle B (2009) Coordination in high-risk organizations: the need for flexible routines. Cogn Technol Work 11(1):17-27

Harris D, Harris FJ (2004) Evaluating the transfer of technology between application domains: a critical evaluation of the human component in the system. Technol Soc 26(4):551-565

Healey AN, Benn J (2009) Teamwork enables remote surgical control and a new model for a surgical system emerges. Cogn Technol Work 11(4):255-265

Hollnagel E (2012) Coping with complexity: past, present and future. Cogn Technol Work 14(3):199-205

Hollnagel E, Cacciabue PC (1999) Cognition, technology and work: an introduction. Cogn Technol Work 1(1):1-6

Hollnagel E, Woods D, Leveson N (2006) Resilience engineering: concepts and precepts. Ashgate, Hampshire

Inagaki T (2006) Design of human-machine interactions in light of domain-dependence of human-centered automation. Cogn Technol Work 8(3):161-167

Inagaki T (2010) Traffic systems as joint cognitive systems: issues to be solved for realizing human-technology coagency. Cogn Technol Work 12(2):153-162

Isermann R, Schorn M, Stählin U (2008) Anticollision system PRORETA with automatic braking and steering. Veh Syst Dyn 46(Supplement 1):683-694

Itoh K, Yamaguchi TP, Hansen J, Nielsen FR (2001) Risk analysis of ship navigation by use of cognitive simulation. Cogn Technol Work 3(1):4-21

Johnson CW (2002) The causes of human error in medicine. Cogn Technol Work 4(2):65-70

Johnson CW (2005) Lessons from the evacuation of the world trade centre, 9/11 2001 for the development of computer-based simulations. Cogn Technol Work 7(4):214-240

Karikawa D, Aoyama H, Takahashi M, Furuta K, Wakabayashi T, Kitamura M (2013) A visualization tool of en route air traffic control tasks for describing controller's proactive management of traffic situations. Cogn Technol Work 15(2):207-218

Kervern GY (1995) Eléments fondamentaux des cindyniques (Fundamental elements of cindynics). Economica Editions, Paris

Kontogiannis T (1999) Management of stressful emergencies. Cogn Technol Work 1(1):7-24

Kylesten B, Nählinder S (2011) The effect of decision-making training: results from a command-and-control training facility. Cogn Technol Work 13(2):93-101

Masson M, Koning Y (2001) How to manage human error in aviation maintenance? The example of a JAR 66-HF education and training programme. Cogn Technol Work 3(4):189-204

McCarthy JC, O'Connor B (1999) The context of information use in a hospital as simultaneous similarity-difference relations. Cogn Technol Work 1(1):25-36

Militello LG, Patterson ES, Bowman L, Wears R (2007) Information flow during crisis management: challenges to coordination in the emergency operations center. Cogn Technol Work 9(1):25-31

Miller JE, Patterson ES, Woods DD (2006) Elicitation by critiquing as a cognitive task analysis methodology. Cogn Technol Work $8(2): 90-102$

Nemeth C (2007) Groups at work: lessons from research into largescale coordination. Cogn Technol Work 9(1):1-4

Nemeth C (2012) Adapting to change and uncertainty. Cogn Technol Work 4(3): 183-186

Nemeth C, Wears RL, Patel S, Rosen G, Cook R (2011) Resilience is not control: healthcare, crisis management, and ICT. Cogn Technol Work 13(3):189-202

Norros L, Salo L (2009) Design of joint systems: a theoretical challenge for cognitive systems engineering. Cogn Technol Work 11(1):43-56
Ouedraogo KA, Enjalbert S, Vanderhaegen F (2013) How to learn from the resilience of human-machine systems? Eng Appl Artif Intell 26(1):24-34

Parush A, Kramer C, Foster-Hunt T, McMullan A, Momtahan K (2014) Exploring similarities and differences in teamwork across diverse healthcare contexts using communication analysis. Cogn Technol Work 16(1):47-57

Perry SJ, Wears RL (2012) Underground adaptations: case studies from health care. Cogn Technol Work 14(3):253-260

Portouli E, Papakostopoulos V, Lai F, Chorlton K, Hjälmdahl M, Wiklund M, Chin E, De Goede R, Hoedemaeker DM, Brouwer RFT, Lheureux F, Saad F, Pianelli C, Abric J-C, Roland J (2006) Long-term phase test and results. Deliverable 1.2.4 of AIDE (Adaptive Integrated Driver Vehicle Interface). Volvo Technologies, Gothenburg

Pritchett AR, Kim SY, Feigh KM (2014) Modeling human-automation function allocation. J Cogn Eng Decis Mak 8(1):33-51

Rashid JHS, Place CS, Braithwaite GR (2013) Investigating the investigations: a retrospective study in the aviation maintenance error causation. Cogn Technol Work 15(2):171-188

Re A, Macchi L (2010) From cognitive reliability to competence? An evolving approach to human factors and safety. Cogn Technol Work 12(2):79-85

Reason J (1997) Managing the risks of organizational accidents. Ashgate, Farnham

Rogalski J (1999) Decision making and management of dynamic risk. Cogn Technol Work 1(4):247-256

Roth EM, Christian CK, Gustafson M, Sheridan TB, Dwyer K, Gandhi TK, Zinner MJ, Dierks MM (2004) Using field observations as a tool for discovery: analysing cognitive and collaborative demands in the operating room. Cogn Technol Work 6(3):148-157

Rudin-Brown CM, Jamson SL (eds) (2013) Behavioural adaptation and road safety: theory, evidence and action. CRC Press, Boca Raton

Rudin-Brown CM, Noy IY (2002) Investigation of behavioral adaptation to lane departure warnings. Transp Res Rec 1803:30-37

Saad F (2006) Some critical issues when studying behavioural adaptations to new driver support systems. Cogn Technol Work 8(3): $175-181$

Salo I, Svenson O (2003) Mental causal models of incidents communicated in licensee event reports in a process industry. Cogn Technol Work 5(4):211-217

Shalin V (2005) The roles of humans and computers in distributed planning for dynamic domains. Cogn Technol Work 7(3):198-211

Smith PJ, Spencer AL, Billings CE (2007) Strategies for designing distributed systems: case studies in the design of an air traffic management system. Cogn Technol Work 9(1):39-49

Stanton NA, Marsden P (1996) From fly-by-wire to drive-by-wire: safety implications of automation in vehicles. Saf Sci 24(1):35-49

Telci E, Maden C, Kantur D (2011) The theory of cognitive dissonance: a marketing and management perspective. Procedia Soc Behav Sci 24:378-386

Turner P, Turner S (2001) Describing team work with activity theory. Cogn Technol Work 3(3):127-139

Upton C, Dohert G, Gleeson F, Sheridan C (2010) Designing decision support in an evolving sociotechnical enterprise. Cogn Technol Work 12(1):13-30

Vaa T (2013) The psychology of behavioural adaptation. In: RudinBrown CM, Jamson SL (eds) Behavioural adaptation and road safety: theory, evidence and action. CRC Press, Boca Raton, pp 207-226 
van Westrenen F, Praetorius G (2014) Maritime traffic management: a need for central coordination? Cogn Technol Work 16(1):59-70

Vanderhaegen F (2010) Human-error-based design of barriers and analysis of their uses. Cogn Technol Work 12(2):133-142

Vanderhaegen F (2013) A dissonance management model for risk analysis. 12th IFAC/IFIP/IFORS/IEA Symposium on Analysis, Design, and Evaluation of Human-Machine Systems, 11-15 August 2013, Las Vegas, USA, pp 381-401

Vanderhaegen F, Chalmé S, Anceaux F, Millot P (2006) Principles of cooperation and competition: application to car driver behavior analysis. Cogn Technol Work 8(3):183-192

Woods DD, Cook RI (2002) Nine steps to move forward from error. Cogn Technol Work 4(2):137-144
Woods DD, Patterson ES, Roth EM (2002) Can we ever escape from data overload? A cognitive systems diagnosis. Cogn Technol Work 4(1):22-36

Xiao T, Sanderson P (2013) Evaluating the generalizability of the organizational constraints analysis framework: a hospital bed management case study. Cogn Technol Work, published online 28 March 2013

Young MS, Stanton NA, Harris D (2007) Driving automation: learning from aviation about design philosophies. Int J Veh Des 45(3):323-338

Zieba S, Polet P, Vanderhaegen F, Debernard S (2010) Principles of adjustable autonomy: a framework for resilient human machine cooperation. Cogn Technol Work 12(3):193-203 